\title{
Jefferson
}

Thomas Jefferson University

$\overline{\text { HOME OF SIDNEY KIMMEL MEDICAL COLLEGE }}$

Jefferson Journal of Psychiatry

Volume 9 | Issue 1

Article 11

January 1991

\section{The Barking Man: A Case Study of Rootwork in Psychiatry}

Harry D. Goldwasser, M.D.

University of North Carolina at Chapel Hill

Follow this and additional works at: https://jdc.jefferson.edu/jeffjpsychiatry

Part of the Psychiatry Commons

Let us know how access to this document benefits you

\section{Recommended Citation}

Goldwasser, M.D., Harry D. (1991) "The Barking Man: A Case Study of Rootwork in Psychiatry," Jefferson Journal of Psychiatry. Vol. 9 : Iss. 1 , Article 11.

DOI: https://doi.org/10.29046/JJP.009.1.009

Available at: https://jdc.jefferson.edu/jeffjpsychiatry/vol9/iss1/11

This Article is brought to you for free and open access by the Jefferson Digital Commons. The Jefferson Digital Commons is a service of Thomas Jefferson University's Center for Teaching and Learning (CTL). The Commons is a showcase for Jefferson books and journals, peer-reviewed scholarly publications, unique historical collections from the University archives, and teaching tools. The Jefferson Digital Commons allows researchers and interested readers anywhere in the world to learn about and keep up to date with Jefferson scholarship. This article has been accepted for inclusion in Jefferson Journal of Psychiatry by an authorized administrator of the Jefferson Digital Commons. For more information, please contact: JeffersonDigitalCommons@jefferson.edu. 


\title{
The Barking Man: A Case Study of Rootwork in Psychiatry
}

\author{
Harry D. Goldwasser, M.D.
}

\section{INTRODUCTION}

Cultures and sub-cultures attempt to describe illness in ways that are most understandable to the people who live in that community. These groups may differ when describing the etiology, course and treatment of any given ailment. Mental illness is just as susceptible to being explained in a manner which differs from group to group. Not surprisingly, psychiatrists trained under the auspices of "mainstream America"- that is, where the Western Judeo-Christian paradigm reigns, may find themselves dismissing symptoms of other sub-cultures. Some patients may have manifestations of true mental illness; others may have symptoms which are culturally sanctioned but which we label as mental illness. We may even misdiagnose behavioral variation among cultural groups as serious disease.

This paper is specifically concerned with the phenomenon of rootwork, a magical system of explaining sickness and health among some people in the United States. More specifically, a case is described where the severe symptoms of one patient went misdiagnosed as a result of cross-cultural confusion. Such misunderstandings can become clearer for those able to think about how mental illness crosses cultures and may become a new entity to that different group of people. Cross-cultural psychiatry is interested in the interface between such different groups. Additionally, difficulties with treatment of one culture's disease by another culture's remedies are discussed.

\section{CASE REPORT}

RW was admitted in October 1988 at a NC State Mental Health facility. He was a 35 year old black male from a small city in southeastern North Carolina. His recent history revealed several recent short admissions to this facility beginning in June, 1988 through the present. More notable were the eleven admissions to his local hospital since 1974.

The patient had previously been diagnosed with chronic undifferentiated schizophrenia and mild mental retardation. His problems were manifested by what he called "spells" which began in 1972 when he was nineteen. These were noted in the hospital as periods when the patient would complain of headache and of his stomach "feeling full." The patient would next begin barking in a very loud voice and would have to be removed from the ward to the quiet room. These barking episodes could last from fifteen minutes to several hours. RW would also

Address correspondence to Dr. Goldwasser at University of North Carolina, Department of Psychiatry. 
report "voices inside my head." Initially, these voices were attributed to three people: his father, "Fruit" and "Rico."

Old discharge summaries indicated that the patient had been on neuroleptics for years and many medication changes had been made during this period. Interestingly, when a new regimen was prescribed, the patient reported getting better for awhile, then "these voices just come back on me." The patient had also taken lorazepam in the past.

The records also revealed that the patient lived with his mother in a somewhat rural setting with several cousins; he was very compliant in keeping his appointments with his local mental health center, having seen the same therapist regularly for over nine years. His frequent past hospitalizations were prompted when, according to his mother, "that fool talk would get too much."

At the beginning of this admission, RW was suffering up to 5-6 spells a day of loud, unnerving barking and other stereotypical movements. These episodes proved so incapacitating that seclusion and even restraint was at times necessary because of his capacity to be violent during them. On admission, he was being treated with haloperidol, carbamazepine and lorazepam.

In speaking with his local therapist, this patient was described as one of her favorites. He was "always courteous, attentive and seemed eager to seek help." She was concerned, however, at the increasing display of violence during his spells. At their last meeting, the patient began barking and chased her into a corner with a chair. She was unsure what else could be offered him.

There seemed to be a definite progression of RW's spells. At any time of the day or night, often with a clear stressor (mother leaving from a visit, food picked off his tray by another patient) he would describe an intense frontal headache. In a few moments, he began what he described as "jaw twistin" " and "water in my jaw." He further described that soon "my mouth starts poppin' and my eyes blink hard. Then my throat goes to tickin' like a clock. Then those voices in my head come on me, and I start barking like a dog, talkin' that fool talk, then I stagger around like I'm drunk, but I'm not."

Amazingly, the patient could imitate himself having a spell. However, there was no mistaking when the real event occurred, as his eyes would glaze over and his affect was quite different. The barking was harrowing and painful to hear, ranging in pitch, inflection and loudness, easily heard throughout the ward.

Early on it was realized that there was a crucial response point in this series. If a staff member could engage RW in some soothing talk and get him to lie down or take an ibuprofen or lorazepam prior to when the barking began, the spell could be aborted. But once the barking started, the entire event ran its course.

It became increasingly clear that the haloperidol and carbamazepine were not targeting his symptoms. In an effort to observe the patient as drug free as possible, all medications were stopped except lorazepam.

The next discovery was almost revelatory: the staff discerned that when RW barked, he was saying "Roy"- - his father's name. This had sounded to us like a dog barking. The patient still admitted to "barkin' like a dog, but barkin' my daddy's name."

Still another observation was that many times after the spell was over, the patient would begin crying. It became evident that he was very distraught and depressed. He was not sleeping well at night and had lost ten pounds during his current stay. Trimipramine was started and we began to talk about why he was sad.

It soon became apparent that RW had a lot to talk about. The patient made it clear that his father had been 'messin' with me since I was one year old ... he put a spell on me." $\mathrm{He}$ 
believed a root was on him and he had spent many years searching for a way to get the root removed. He had travelled to Charleston, SC to see the strongest root doctor known to him. But the treatment was unsuccessful. He estimated that he and his mother had spent several thousand dollars and travelled to twenty different root doctors in hopes of freeing him from this curse. He believed that at one point his father had taken some "graveyard dust" and placed it in his path, thus placing the root on him.

He went on to list the many people "inside" his head who had something to do with the rooting in addition to his father, but it was unclear what relationship they had to his illness.

RW's parents had separated when he was nine or ten. He enjoyed an extremely close relationship with his mother who called him "Brother." He had five older sisters whom his father always cared for and pampered, as opposed to RW. He described in touching detail the love he held for his mother and how she tried to help him with his root; also obvious was the mother's dependency on RW.

After three weeks of this hospitalization a remarkable delineation of RW's illness became apparent. When he was not in a "spell," his mental status exam was completely normal. At such times RW had no psychotic features, no disturbances in appearance, speech, thought content, judgement or orientation. Additionally, he had a good deal of insight into his problem. His mood was at times depressed, but never of a psychotic nature. And yet, when his spell would come on him, a completely different mental status emerged: RW became confused, aggressive, unpredictable and suffered from auditory hallucinations. The old diagnosis of schizophrenia began to be questioned due to both the poor response to neuroleptics and the sudden return of clear sensorium and good functioning after a "spell" was over.

Seizures had been considered earlier in this hospitalization, but three separate EEGs were normal, as was a post-spell prolactin level. A head CT was normal as well. Tourette's Syndrome was also thought of, but a neurology consult considered that this was not an appropriate diagnosis. Dissociative disorders were strongly considered, and indeed this was the working diagnosis at the end of the first month of hospitalization. Admittedly, it was a challenge to explain all these symptoms based on "roots" alone.

RW continued to show signs of integrating his illness to insight. He asked almost daily, "what is this happening to me . . why does this barking keep coming back?" He was a favorite on the ward, and when not acutely ill remained friendly, warm and interactive.

The patient was unable to provide me with information justifying his hatred for his father nor many other childhood memories. Early trauma was suspected. He continued to respond well to the anti-depressant and had been off haloperidol for over two months; the number of spells began to drop to one to two a day. He was sleeping well at night and said he was feeling better than he had ever remembered.

As RW stabilized, it was thought that amobarbitol interviews could be useful in further describing and ultimately diagnosing his illness. Such interviews have been used extensively in the past, and often provide some therapeutic effects as well (1). These began the second month of hospitalization. The patient was made aware of the intent and procedure of the interviews, and eagerly agreed and looked forward to them in hopes of "getting this stuff out of my head."

Over the next few weeks, three amobarbitol interviews were conducted. In the first, RW recalled many early memories. When he was about six, his father took him regularly to prostitutes and would set him down at the foot of the bed or in the doorway while the father would proceed to have sex. Often the women would set a plate of food down for RW before beginning. His father made him promise to never tell his mother what went on; if he did, his father would stop bringing him.

Eventually, after a few years of this, RW told his mother, unable to withstand the conflict 
such events caused him. The mother took RW with her and shot up the house the father was found in.

He went on to talk of how badly his father treated his mother, and remembered an argument which became violent. RW was locked up in the bathroom while the parents fought. His dog began barking furiously and tried to intervene in the fight and would run back and forth to where RW was trapped.

When RW was fourteen, his father returned from a lengthy separation. He began to bark at his father, who called him crazy and then left again.

When asked of his earliest memory, RW reported being held down while his father laughed at his genitals, because they were "cold and sucked in me."

After this interview, the patient went four days without an episode. He then had a barking spell, and requested a second interview since he sensed some connection between the last and his quiet four days. Interestingly, he became agitated and began with his preliminary mouth popping as we prepped him for the injection, indicating that a full spell would come on soon. As the amobarbitol was injected, he quickly relaxed and said "that got my spell down."

At this interview, he remembered with great pain people in his community who had laughed at him since 1972; the whole town knew him as the "barking boy" who had been rooted. He went on to talk about his ability to work in the local mill when he was nineteen until he fancied a girl from afar and his spells began. He thought his father had convinced her to place a root as well, in order to take away his sexual drive. He cried, "I've never done anything to anybody ... why did they do this to me?"

RW stopped barking after this, but had other symptoms such as food getting caught in his throat which choked him. His mother finally convinced his father to visit, in hopes that once and for all the root could be removed. This was too much for RW. He became violent at the visit, staggering around. He was no longer barking. He was screaming, "you tell Roy to stay away from me" over and over again, throwing furniture about.

The last amobarbital interview was done to reinforce that his father was gone and to suggest that the root was off him. We practiced relaxation techniques while under the amobarbitol in hopes that RW could cope with these intense feelings for his father. In later days, we continued hypnotic relaxation exercises.

RW stayed with the hospital for another month, making his stay over four months. By this time, he had again calmed considerably, and was suffering from zero to four spells a day. $\mathrm{He}$ was sleeping well, and feeling better, although still asked "when will these things leave me for good?" He remained on the anti-depressant and clonazepam. He was discharged to a mother anxious to have him home, and seemed to understand that his life would perhaps never be completely free from spells, but he was less troubled by them. He wanted to resume with his old therapist. He also greatly looked forward to getting ready the above ground pool his mother had bought years ago. It was his job to keep it clean and prepare it for the summer.

\section{DISCUSSION}

As patients, those involved with psychiatric services often have complex stories which unfold according to a natural progression. We dutifully record these, perhaps unaware of what shall be revealed in days to come. Many patients may not feel comfortable telling their experience, especially if the listener is from a different cultural background. They may fear ridicule, misunderstanding and poor treatment options. As time progressed, RW's story became a complex one, without clear 
answers for treatment; his plight also revealed the limits of psychiatry to understand his different world view.

Even when we think we are acting as non-biased, well trained professionals, patients can challenge our basic ability to help. I discovered this when treating R.W. Together we tried, with some success, to break a twenty year spell of "roots" until he met a tragic end. In retrospect, RW taught me the powerful language of his society, and how the universal dynamic struggles of becoming an adult are played out within the cultural fabric.

All cultures envelop magical or non-natural explanations for their emotional and physical illnesses (2). This may not seem very apparent to a modern, "anglicized" American; but recall the last time you heard or said, in response to a vague bodily complaint, "it must have been something I ate." This is, in effect, ascribing a not yet validated claim to illness in hopes that the symptom can be confined, or seemingly better understood. Roots are another way that people seek to make sense of their world.

Roots and rootwork are the more comprehensive umbrella for terms that include hoodoo, conjure medicine and voodoo (although this is not the same as practiced in Haiti). The essence of rootwork is the belief that illness or even death may come on a person as a result of a hex or curse. Rootwork is thought to originate in the slaves of the Antebellum South; it is seen by experts as an amalgamation of beliefs from traditional African medicine and Catholicism first merging in the West Indies, then entering the U.S. via slave routes to New Orleans where it met American Indian herbal lore $(3,4,5)$. It is unclear why rootwork has survived several hundred years, but as sociologist Holly Mathews says, "for many black Americans still living under conditions of poverty, racism, and social uncertainty, it is not surprising that the promise of magic holds a certain appeal" (5). Today, most people who believe in roots are poor, rural blacks in the Deep South, although this system spread with migrating blacks into urban northern cities in the 1950-60's (6); certainly rootwork extends beyond black culture, as white root doctors attest.

Roots are spells placed by root workers with the intent to harm another person. These spells may be placed with or without the aid of a "bad" root doctor. Victim's friends, co-workers or extended family members may use roots as a means of revenge. Roots can also be used at times when a business deal goes awry, love is rejected or jealousy felt. "Good" root doctors never originate roots; their job is to remove them. They seem to possess innate spiritual abilities to dissolve the spell and even place it back on the one who sent it (7).

Usually, roots are placed physically on the victim, using cloth, dust, hair or potions, but walking through sprinkled dust is sufficient to set the hex. Symptoms of roots include burning, itching and rashes on the skin. Such skin complaints are frequent, and often thought to result from animals (snakes, spiders, lizards, toads) placed under the skin $(4,5,7)$. Paralysis and numbness are often reported. Severe GI symptoms of nausea, vomiting, bloating and diarrhea are common. One reported case describes pseudocyesis caused by roots (8).

According RW, good root doctors stay very busy treating their clients; those who feel their gift is God-given may charge nothing for their services. Others, such as "the 
most powerful one" RW knew of charged over two thousand dollars for her work. It seems that like mental health workers, root doctors utilize personal and family interviews, listen well and try to help the victims change for the better. In addition, a variety of potions and herbs may be used. Interestingly, most work well with physicians and will refer to medical centers when appropriate. Unfortunately, few cases reported seem able to utilize the root doctor once the patient is brought to medical attention. It is unfortunate to lose a potentially strong ally by not involving the root doctor intreatment. This does not have to happen; In other cultural systems, American Indian Medicine Men and Women have treated the sick concomitantly with the Indian Health Service, with good results (9).

Difficult situations arise when a rootwork victim presents with psychiatric symptoms. Certainly the victims of rootwork may be truly psychotic of suffer from a chronic mental illness. But, what may appear as bizarre delusions to those unfamiliar with thee culture may not represent a break from reality for the patient. On the other hand, many patients claiming roots may not be psychotic, yet may have serious psychopathology (4).

Again, there may be an inclination to categorize a patient's complaint about snakes under his skin according to cultural norms which fail to encompass an understanding of root beliefs. Such a failure, on the part of a physician, can cause a patient to remain mute because he has come to expect ridicule upon speaking. Quite simply, if physicians conclude that presentations founded upon unfamiliar cultures as ignorant, foolish, or unenlightened, then not only will we fail to gain our patients' confidence, we will not hear or understand the information which might allow us to be effective psychiatrists for various groups of people.

Several cases have been reported of psychotic-appearing "rooted" patients resolving just days after being hospitalized, under the care of an understanding physician and team who have some knowledge of rootwork $(4,8,10)$. In this way, as unscientific as it may feel, physicians can work with patients who have indeed been rooted and whose symptoms can be treated as such. Alternatively, we can also become aware of those patients who have brain dysfunction resulting in "true" cross-cultural mental illness (i.e., schizophrenia), yet think they are rootwork victims.

Certainly this is easier said than done, and it is difficult to know what tenets could clearly distinguish culturally appropriate symptoms from psychotic ones. The role of culture, however, is made more apparent when the context is considered and family interviewed. For RW, rootwork was very common in his community and his mother believed strongly that it was the source of his problems. He suffered from very complex and seemingly bizarre thoughts, and was considered to be psychotic for many years. One of the factors which led to the removal of his diagnosis as schizophrenia was his perfectly normal mental status exam between his episodes.

The literature reports two cases of rooted patients successfully treated with hypnosis and psychotherapy $(11,12)$. It is thought by Snell that hypnosis may be the treatment of choice for hexed patients brought to medical attention, as victims are perhaps highly suggestible. Success for the hypnosis patient was not gauged by dispelling the root but rather by allowing the patient to live less tormented with it. It is unknown how effective therapy of any type is for those rooted. Nevertheless, root 
patients should be treated as any other, with an empathetic, non-judgemental, even accepting, demeanor. In that way, reasonable options from the patient's standpoint can be made available.

I had mixed feelings at RW's departure, unsure of what had helped. He had initiated me into a perplexing and mysterious world which, as a psychiatrist, I had previously scoffed at out of fear and intellectuality.

It seems clearer now that RW suffered from a dissociative disorder, although a more precise diagnosis is difficult to make. While it is true that he did have hallucinations and, at times, lose touch with reality, it was his clear sensorium between spells that makes his problem not in the realm of thought disorders. Rather, he was able to relive the past traumas of his life in an altered state of self. It remains unclear if this was used as a protective or simply necessary way for him to exist with pain from the past and present. Additionally, it appears that his culturally acceptable model of rootwork provided a framework for him to understand his symptoms.

Three months after his discharge, RW was cleaning his mother's pool, had a spell, and drowned. It seems incongruous to say roots were not the source of his illness; yet, for psychiatry to admit such, we must be better prepared to understand his culture, or any other different from our own.

\section{REFERENCES}

1. Perry JC, Jacobs D: Overview: Clinical applications of the amytal interview in psychiatric emergency settings. American Journal of Psychiatry 139:552-559, 1982.

2. Murdock GP, Wilson S, Frederick V: World distribution of theories of illness. Ethnology 17:449-470, 1978.

3. Rocereto LR: Root Work and the Root Doctor. Nursing Forum 12:414-426, 1973.

4. Hillard JR: Diagnosis and treatment of the rootwork victim. Psychiatric Annals 12:705$714,1982$.

5. Mathews HF: Rootwork: Description of an Ethnological System in the American South. Southern Medical Journal 80:885-891, 1987.

6. Tingling DC: Voodoo, Root Work, and Medicine. Psychosomatic Medicine 24:483-490, 1967.

7. Ness RC, Wintrob RM: Folk Healing: A description and synthesis. American Journal of Psychiatry 138:1477-1481, 1981.

8. Kismet CP: A case of pseudocyesis caused by "roots". American Journal of Obstetrics and Gynecology 107:801-803, 1970.

9. Manson SM, Walker RD and Kirlahan DR: Psychiatric assessment and treatment of American Indians and Alaska Natives. Hospital and Community Psychiatry 38:165-173, 1987.

10. Wintrob RM: The influence of others: Witchcraft and rootwork as explanations of behavior disturbances. The Journal of Nervous and Mental Disorders 156:318-326, 1973.

11. Snell JE: Hypnosis in the treatment of the "hexed" patient. American Journal of Psychiatry 124:311-316, 1967.

12. Hillard JR, Rockwell WJK: Dysethesia, witchcraft, and conversion reaction. GAME 240: 1742-1744, 1978. 